\title{
SOME ESTIMATES FOR THE BILINEAR FRACTIONAL INTEGRALS ON THE MORREY SPACE
}

\section{XiaO Yu, XiangXing TaO, Huihui Zhang and Jianmiao Ruan}

Abstract. In this paper, we are interested in the following bilinear fractional integral operator $B \mathscr{I}_{\alpha}$ defined by

$$
B \mathscr{I}_{\alpha}(f, g)(x)=\int_{\mathbb{R}^{n}} \frac{f(x-y) g(x+y)}{|y|^{n-\alpha}} d y,
$$

with $0<\alpha<n$. We prove the weighted boundedness of $B \mathscr{I}_{\alpha}$ on the Morrey type spaces. Moreover, an Olsen type inequality for $B \mathscr{I}_{\alpha}$ is also given.

Mathematics subject classification (2010): 42B20,42B25.

Keywords and phrases: Weighted norm inequalities, bilinear fractional integral, dyadic grids, Morrey spaces, Olsen type inequalities.

\section{REFERENCES}

[1] R. AdAms, A note on Riesz potential, Duke Math. J., 42, 4 (1975), 765-778.

[2] F. Bernicot, D. Maldonado, K. Moen and V. Naibo, Bilinear Sobolev-Poincaré inequalities and Leibniz-type rules, J. Geom. Anal., 24, 2 (2014), 1144-1180.

[3] J. Chen And D. Fan, Some bilinear estimates, J. Korean Math. Soc., 46, 3 (2009), 609-620.

[4] J. ChEn AND D. FAn, Rough bilinear fractional integrals with variable kernels, Front. Math. China, 5, 3 (2010), 369-378.

[5] J. CHEN AND D. FAN, A bilinear fractional integral on compact Lie groups, Canad. Math. Bull., 54, 2 (2011), 207-216.

[6] S. Chen, H. WU AND Q. XUE, A note on multilinear Muckenhoupt classes for multiple weights, Studia Math., 223, 1 (2014), 1-18.

[7] X. Chen And Q. XuE, Weighted estimates for a class of fractional type operators, J. Math. Anal. Appl., 362, 2 (2010), 355-373.

[8] F. Chiarenza And M. Frasca, Morrey spaces and Hardy-Littlewood maximal function, Rend. Math. Appl., 7, 3-4 (1987), 273-279.

[9] J. Conlon AND J. REDONDO, Estimates on the solution of an elliptic equation related to Brownian motion with drift, Rev. Mat. Iberoam., 11, 1 (1995), 1-65.

[10] Y. Ding AND C. Lin, Rough bilinear fractional integrals, Math. Nachr., 246/247, (2002), 47-52.

[11] Y. FAn And G. GaO, Some Estimates of Rough Bilinear Fractional Integral, J. Func. Spaces Appl., 406540, (2012), 17 pages.

[12] S. Gala, Y. Sawano And H. TAnaKa, A new Beale-Kato-Majda criteria for the 3D magnetomicropolar fluid equations in the Orlicz-Morrey space, Math. Methods Appl. Sci., 35, 11 (2012), 1321-1334.

[13] S. Gala, Y. Sawano And H. TanaKa, On the uniqueness of weak solutions of the $3 D M H D$ equations in the Orlicz-Morrey space, Appl. Anal., 92, 4 (2013), 776-783.

[14] L. Grafakos, On multilinear fractional integrals, Studia Math., 102, 1 (1992), 49-56.

[15] L. Grafakos AND R. Torres, Multilinear Calderón-Zygmund theory, Adv. Math., 165, 1 (2002), $124-164$.

[16] J. Garcia-Cuerva And J.L. Rubio de Francia, Weighted Norm Inequalities and related topics, North Holland Mathematics Studies 116, North Holland, Amsterdam, 1985. 
[17] Q. HE AND D. YAN, Bilinear fractional integral operators on Morrey spaces, arXiv:1805.01846v2 (2018).

[18] C. HoAng And K. Moen, Weighted estimates for bilinear fractional integral and their commutators, Indiana Univ. Math. J., 67, 1 (2018), 397-428.

[19] T. IIDA, A Characterization of a Multiple Weights Class, Tokyo J. Math., 35, 2 (2012), 375-383.

[20] T. IIDA, Weighted norm inequalities on Morrey spaces for linear and multilinear fractional integrals with homogeneous kernels, Taiwan. J. Math., 18, 1 (2014), 147-185.

[21] T. IIDA, Multilinear fractional integral operators on weighted Morrey spaces, Harmonic analysis and nonlinear partial differential equations, RIMS Kôkyûroku Bessatsu, B49, (2014), 13-31.

[22] T. IIDA, Weighted estimates of higher order commutators generated by BMO-functions and the fractional integral operator on Morrey spaces, J. Inequal. Appl., 2016, (2016), 23 pp.

[23] T. IIDA, Y. Komori-Furuya And E. SATO, New multiple weights and the Adams inequality on weighted Morrey spaces, Sci. Math. Jpn., 74, 2-3 (2011), 145-157.

[24] T. IIDA, Y. Komori-FuruYA And E. SATO, The Adams inequality on weighted Morrey spaces, Tokyo J. Math., 34, 2 (2011), 535-545.

[25] T. IIDA, E. SATO, Y. SAWANO AND H. TANAKA, Weighted norm inequalities for multilinear fractional operators on Morrey spaces, Studia Math., 205, 2 (2011), 139-170.

[26] T. IIDA, E. Sato, Y. SAWANo And H. TANAKa, Multilinear Fractional Integrals on Morrey Spaces, Acta Math. Sin. (Engl. Ser.), 28, 7 (2012), 1375-1384.

[27] Y. KOMORI-FURUYA, Weighted estimates for bilinear fractional integral operators: a necessary and sufficient condition for power weights, Collect. Math., 71, 1 (2019), 25-37.

[28] Y. KOMORI-FuruYA, Weighted estimates for bilinear fractional integral operators, Math. Nachr., 292, 8 (2019), 1751-1762.

[29] Y. Komori-FurUYA AND S. Shirai, Weighted Morrey spaces and a singular integral operator, Math. Nachr., 282, 2 (2009), 219-231.

[30] C.E. Kenig And E.M. Stein, Multilinear estimates and fractional integration, Math. Res. Lett., 6 , 1 (1999), 1-15.

[31] A. LERNER, On an estimate of Calderón-Zygmund operators by dyadic positive operators, J. Anal. Math., 121, (2013), 141-161.

[32] A. Lerner, S. Ombrosi, C. PÉrez et Al., New maximal functions and multiple weights for the multilinear Calderón-Zygmund theory, Adv. Math., 220, 4 (2009), 1222-1264.

[33] K. Moen, Weighted inequalities for multilinear fractional integral operators, Collect. Math., 60, 2 (2009), 213-238.

[34] K. MoEn, New weighted estimates for bilinear fractional integral operators, Trans. Amer. Math. Soc., 366, 2 (2014), 627-646.

[35] C. Morrey, On the solutions of quasi-linear elliptic partial differential equations, Trans. Amer. Math. Soc., 43, 1 (1938), 126-166.

[36] B. Muckenhoupt, Weighted norm inequalities for the Hardy maximal function, Trans. Amer. Math. Soc., 165, (1972), 207-226.

[37] B. Muckenhoupt And R. WheEden, Weighted norm inequalities for fractional integrals, Trans. Amer. Math. Soc., 192, (1974), 261-274.

[38] P. Olsen, Fractional integration, Morrey spaces and Schrödinger equation, Comm. Partial. Differ. Equa., 20, 11-12 (1995), 2005-2055.

[39] Y. SAWANO, S. SugANO AND H. TANAKA, A note on generalized fractional integral on generalized Morrey spaces, Bound. Value Probl., 835865, (2009), 18 pages.

[40] Y. Sawano, S. Sugano And H. TAnaKa, Generalized Fractional Integral Operators and Fractional Maximal Operators in the Framework of Morrey Spaces, Trans. Amer. Math. Soc., 363, 12 (2011), 6481-6503.

[41] Y. SaWANO, S. SUGANO AND H. TANAKA, A bilinear eatimate for commutators of fractional integral operators, RIMS Kôkyûroku Bessatsu, B43, (2013), 155-170.

[42] H. TANaKa, Morrey spaces and fractional integrals, J. Aust. Math. Soc., 88, 2 (2010), 247-259.

[43] X. Wu AND J. ChEn, Boundedness of fractional integral operators on $\alpha$-modulation spaces, Appl. Math. J. Chinese Univ., Ser. B, 29, 3 (2014), 339-351.

[44] X. YU AND S. LU, Olsen type inequalities for the generalized commutator of multilinear fractional integrals, Turk. J. Math., 42, 5 (2018), 2348-2370. 
[45] Y. Zhong AND J. Chen, Modulation space estimates for the fractional integral operators, Sci. China Math., 54, 7 (2011), 1479-1489. 